\title{
Replies to Brewer, Gupta, and McDowell
}

Susanna Siegel * Round 2

\section{Reply to Brewer}

My inferentialist analysis of hijacked experiences allows that these experiences can be conclusions of inference. If experiences are conclusions of inference in these cases, what kinds of mental states can figure as the inputs to the inferences?

In Brewer's initial gloss on these cases, the input to such inference is always another experience, and that experience always has a baseline amount of epistemic power. He then asks how this gloss would apply to memory color, where one ends up experiencing a banana as yellowish.

The answer is that it wouldn't because the gloss is too limited. The inputs to inferences that culminate in experiences can be informational states of the perceptual system as well as cognitive states such as beliefs, suspicions fear (more exactly, its representational component, as well as such components of other emotions). Inferences to experience can occur wholly within the perceptual system. ${ }^{1}$

In my analysis of the case of memory color, the ultimate status of the experience depends on the structure of the underlying processing. ${ }^{2}$ The conclusion is false, but this fact alone does not worsen the inference. An inference to a false conclusion could be epistemically good. It will be a poor inference, I claim, when information indicating that the banana is grey is not given its due weight, or the prior assumption that bananas are yellow is given too much weight, or both. Here, there is no other experience that figures in the inference. A fortiori there is no positively charged experience that figures as an input to the inference. So premise E1 in Brewer's reconstruction is not part of my analysis. There is no greyish appearance, either in the actual experiments (as they're typically interpreted) or in the

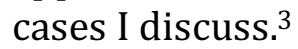

It strikes me as incoherent to say that a single experience at a time both presents the same visible parts of a banana as two different hues at once, greyish and yellowish. If Brewer thinks this may be my view, I wonder why he did not criticize it on these grounds.

In line with the mistaken assumption that perceptual inputs are always experiences that retain baseline epistemic power, Brewer takes me to be committed to a "baseline experiential input immune from influence" by prior assumptions, and then says this

\footnotetext{
${ }^{1}$ Part 3 of Siegel (2017). Jenkin (ms) argues that intra-perceptual processes are sometimes responses to reasons.

2 Siegel (2017), chapter 6.

${ }^{3}$ An exception to most other interpreters of the phenomenon is Zeimbekis (2013), who argues that memory color is always post-perceptual, and so allows that experiences in memory color are veridical.
} 
commitment creates instability. But there is no such commitment. Part of what makes information processing perceptual is that it takes in information from the environment. The importance and interest of the phenomena that motivate the Rationality of Perception thesis stem from the fact that experiences can occur far downstream of such inputs. Phenomenologically, experiences are passive and receptive, but informationally, they can in principle be heavily shaped by one's prior outlook. When that happens, any epistemology of perception that attributes epistemic powers to perceptual experience has some explaining to do. It either has to remove the impression that the prior outlooks can change the epistemic role of experience, or else account for its impact.

Brewer asks what differentiates the Müller-Lyer illusion from illusions generated by hijacked experiences such as Jill's. In principle the Müller-Lyer could be generated by a rationally evaluable inference, and then on my view the epistemic status of the experience would depend on the epistemic status of the inferential inputs, just as with any inference. For instance, if the experience is inferred from a well-founded assumption that the two sets of flags at the end of the lines indicate a difference in length, the resulting experience could be well-founded. And if there is no rationally evaluable inference that generates the Müller-Lyer illusion, then that fact differentiates it from the hijacked experiences I analyze. The key distinction here is between rationally evaluable inferences to experience, and transitions that are also sometimes called "inference" in Psychology but do not redound well or poorly on the subject's rational standing.

Brewer also asks: "How can [presentational] phenomenal character be a source of positive epistemic charge", if this kind of phenomenal character can be shared between experiences with different etiologies that affect the epistemic role of the experience? My answer is that presentational phenomenology makes a contribution to epistemic charge, and that contribution meets with other factors to determine the valence and magnitude of epistemic charge an experience has. In the simplest version, presentational phenomenal character determines a valence and pro tanto magnitude of epistemic charge, which can then be augmented or reduced by other sources of positive or negative charge. The amount of epistemic charge an experience is adjusted upward or downward from the baseline, depending on the inferential route to the experience, if the experience is result of an inference.

In more detail: I distinguish three ways for presentational phenomenal character ground positive epistemic charge, compatibly with the possibility that other factors such as hijacking can modulate the epistemic charge that an experience ultimately carries. These three ways give presentational phenomenal character with a weak, strong, or intermediate roles in grounding epistemic charge. The paragraph above describes the strong role for presentational phenomenal character. In its weak role, presentational phenomenal character makes it the case that experience has an epistemic charge, but other factors such as its psychological precursors are needed to determine its valence and magnitude, and these factors can include hijacking. And in its intermediate role, presentational phenomenal character suffices to give an experience baseline amount of positive epistemic charge, absent defeaters or hijacking factors. 
All three roles support the conclusion that experiences are epistemically charged, and all of them allow that presentational phenomenological can contribute the same thing to experiences that end up with different epistemic powers, due to etiological differences. ${ }^{4}$

Brewer mistakenly assimilates the idea the presentational phenomenal character contributes to epistemic charge to a distinct claim which I reject, which is that presentational phenomenology "contributes a level of experiential representation untainted in any way by the subject's prior outlook." A hijacked experience ends up with its content in part because of hijacking factors. ${ }^{5}$ Its content is not fixed entirely by phenomenal character, but instead, both its phenomenal character and its content are determined in part by hijacking factors. Its presentational phenomenological character plays a role in determining its epistemic power, on my picture, but the role it plays is modulated by hijacking in one of the three ways I just described, corresponding to the weak, strong, or intermediate roles for presentational phenomenal character.

${ }_{4}^{4}$ There is more discussion of this point in Siegel (2017), chapter 3.

${ }^{5}$ And if the Factive Explanatory Constraint is false, veridical and epistemically powerful experiences can end up with contents via this route as well. 


\section{Reply to Gupta.}

\section{Gupta on the scope of the Downgrade thesis}

Gupta suggests that the plausibility of the Downgrade thesis would not be supported by many accounts of experience. "If one subscribes to the idea that experience represents only appearance properties (as is argued in Hill 2014)", he writes, "and one takes experience to warrant only the attribution of appearances of properties ("e.g. "looks angry"), then there is little plausibility to the idea that etiology affects rational significance". By "rational significance" here he says he means the same as "the epistemic power of experience" (fn 30).

Let's distinguish appearance properties that vary across the perceptual constancies of color, shape, and size, from the broader category of 'looks'-properties, which are properties of looking $\mathrm{F}$ for any $\mathrm{F}$, including the properties of being angry and being spherical. Anger and sphericality are then not appearance properties, but of course it is possible for people to look to angry and for a ball to look spherical.

The idea that experiences both represent only appearance properties and warrant only beliefs that things have appearance properties would have the consequence that a perceptual experience cannot give you reason to believe that a ball is spherical. It would also have the consequence that a tree has the height that it constantly looks to have as you move closer to it and its appearance properties change.

Such a view seems implausible on its own, as we can often easily form justified beliefs about how tall things are or what volumetric shapes they haves on the basis of such experiences. The phenomenology of perceptual experience includes the constancies.

It therefore wouldn't be much of a cost, if this position did not sit well with the Downgrade thesis, which says that the etiology of experience can affect its epistemic power to provide justification to beliefs formed on its basis.

Consider the slightly more plausible position that experiences present us only with appearance properties, while justifying us only in believing that things have 'looks' properties (including appearance properties). Gupta thinks the Downgrade thesis would lose plausibility if this position were correct. Why?

I think Gupta is assimilating the proposition Jack looks angry, in which a relational property "looks angry" is attributed to Jack, with a proposition about experiences of the sort one could form on the basis of introspection, such as one I might express by saying "I am having an experience that presents Jack as angry". When Jill's unfounded suspicion that Jack is angry helps generate her experience of him as angry, the Downgrade thesis says that her experience can't then give her the usual amount of reason to believe he's angry. Even if this much is granted, it seems implausible to Gupta that the etiology of Jill's experience could 
detract from the well-foundedness of her introspective belief about the type of experience she is having.

I agree with this last point. But it does not reflect poorly on the Downgrade thesis, for two separate reasons.

First, it would be a strange theory of experience that limited the propositions we can justifiably believe on the basis of experience to introspective beliefs, if the contents of experience characterized only external objects and our relations to them. So once again, if it turned out that the Downgrade thesis didn't sit well with a theory like this, one should just shrug.

Second, my theory of downgrade relativizes downgrade to a content of experience. Jill's experience is downgraded relative to the content "Jack is angry". The epistemic compromise in Jill's experience then affects the role of experience in justifying subsequent beliefs, only when the contents relative to which the experience is downgraded are relevant to the experience's justificatory role.

The downgrade of Jill's experience will therefore not affect the epistemic role of her experience with respect to introspective beliefs, when it's not by virtue of having those contents that the experience gives Jill reason to ascribe to herself the property of having such an experience. (And according to some theories of self-knowledge, the contents of experience are never relevant to justifying introspective beliefs). By contrast, if Jill's experience contents included self-representational contents such as "I am having an angerexperience", then those could be relevant to justifying introspective beliefs. But an experience could be downgraded relative to "Jack is angry" without being downgraded relative to "I am having an anger-experience". ${ }^{6}$

Gupta also suggests that the plausibility of the Downgrade thesis depends on the thesis that "rich" properties such as being angry can be represented in experience. But this isn't so. Suppose that Jill's unfounded fear generate an experience with "low-level" properties (such as furrowed brow and clenched mouth) on the basis of which one could reasonably judge that someone is angry. If the experience presenting these properties was epistemically downgraded, it would detract from the epistemic power of experience to justify the belief that Jack is angry.

What about the belief that Jack looks angry, where this is a relational property attributed to Jack, rather than a belief about the character of one's experience? If Jill's experience attributes to the Jack the property of looking angry, then it is epistemically downgraded if her unfounded fear helps generate an experience that attributes this property to Jack. Jill gets less reason than she otherwise could from her experience to believe that Jack has this relational property.

${ }^{6}$ There is more discussion of this issue in footnote 12 of Siegel (2017). 
The plausibility of the Downgrade thesis is thus less sensitive to ancillary assumptions about experience than Gupta supposes.

\section{Minimal units of epistemic power}

In discussing hijacked experiences, Gupta swaps my term "epistemic power" for "rational significance of experience". I think this seemingly innocuous terminological shift leads to confusion.

Gupta formulates his theory of perceptual justification in terms of rational significance, because he thinks experiences make transitions between Guptarian views rational, rather than harboring epistemic power that it can transmit to beliefs. By contrast, my thesis that experiences can be rational or irrational depending on their psychological precursors says that experiences on their own can manifest a rational status, which I call epistemic charge, and that epistemic charge can be transmitted to beliefs formed on the basis of the experience. Psychological precursors can influence the valence and amount of epistemic charge that an experience has, relative to a content.

In discussing hijacked experiences, Gupta writes:

"Suppose we say that experiences render beliefs well-founded not in isolation but only in conjunction with ... other factors, including...the relevant antecedent beliefs being justified. On this proposal, the downgrade applies not to the rational significance of experience taken in isolation but to the 'minimal unit'...consisting of the experience and these other factors. This move, plausible though it is, supports Siegel's thesis only on a reading that drains it of all its novelty...Siegel's thesis on this reading provides no reason to rethink experience and the processes leading to it."

Here Gupta is implicitly distinguishing between two theses. First, there's the central thesis I defend in The Rationality of Perception:

(a) Experiences can have a status as rational or irrational that can be influenced by its psychological precursors, where this status determines its epistemic power to provide justification.

Second, there's a thesis closer to Gupta's own position:

(b) Experiences have to be combined with other positive factors to form a minimal unit that provides justification. They cannot provide justification on their own under the right negative conditions (no defeaters, or no defeaters and no hijacking), because the minimal unit that can provide justification always includes more than experience.

Gupta then interprets "Siegel's thesis" as taking the form of thesis (b). He is exploring the idea that when experiences combine with an unjustified background belief, the unit of those two things together provides less justification than the experience together with a justified background belief could provide. 
There is no version of Siegel's thesis that takes the form of thesis (b). The effect of hijacking, on my analysis, is that the influence of the background belief on experiences downgrades the experience. For instance, Jill's unfounded suspicion can reduce the epistemic power of her experience of Jack as angry to provide justification for her to believe that Jack is angry. Here, Jill's experience remains a minimal unit that manifests an epistemic charge. The fact (as I see it) that Jill's experience is downgraded by etiology does not make the minimal unit that provides the reduced amount of justification encompass both her experience and the unfounded suspicion. The minimal unit is not something bigger than Jill's experience to which her experience belongs.

An analogy may help bring the key claim into focus. Suppose I believe on poor grounds that each stalk of broccoli is a giant green bacterium. My belief is ill-founded. From this belief (which let's call B) together with my belief that your fridge contains broccoli, I conclude that your fridge contains a giant green bacterium. My conclusion is ill-founded, and that's because it inherits ill-foundedness from belief B. Belief B, by virtue of its etiology, manifests the poor epistemic status and transmits it to my conclusion. The poor grounds that figure B's etiology help explain my route to my ill-founded conclusion. But B all by itself manifests an epistemic status, and so there no greater minimal unit to which it must belong to transmit its ill-foundedness to my conclusion.

\section{Gupta on backdoor justification}

Gupta last point is that nothing prevents Jill's perceptual belief that Jack is angry from being well-founded, because she can reason her way to this conclusion from claims (5), (6), and (7). My first reply is that if Jill forms her belief that Jack looks angry (claim (5)) on the basis of her anger-experience, then the belief is ill-founded, if construed as attributing a relational property to Jack.

If instead claim (5) is construed as a claim about Jill's experience (as she would put it, "I am having an experience that presents Jack as angry"), then Gupta's point is similar to an observation made by Smithies (2018). Both argue that Jill has a way to form a well-founded belief that Jack is angry without relying on her downgraded experience. She therefore also has reason to form the belief that Jack is angry, and that reason does not include her downgraded experience.

None of that is at odds with the thesis Gupta calls "Siegel's datum", which he defines as "Jill's experience does not render it rational for Jill to judge that Jack is angry". Here too, substituting the idea that a transition from experience to judgment is rational is importantly different from the idea that experience provides ground for a judgment. The route Gupta describes to judging "Jack is angry" may in some sense be a transition from an experience to a judgment, but it is not made on the basis of experience. My "datum" is that hijacked experiences relative to a content $\mathrm{C}$ do not provide justification for believing $\mathrm{C}^{7}$ If there is a route to well-founded belief in $C$ that bypasses experience, then the subject faces conflicting normative pressures. (A similar issue arises in McDowell's comment).

\footnotetext{
7 I don't consider this a datum. I argue for it in chapter 4 of The Rationality of Perception.
} 
Siegel / Replies to Brewer, Gupta, and McDowell 


\section{Reply to McDowell}

It is a question for Psychology whether fear, suspicion, or vanity can influence perceptual experiences, in a way that the cases of Vivek and Jill would illustrate. By contrast, it isn't an empirical question whether either of the two positions on the structure of experience that McDowell describes are correct. McDowell thinks those positions rule out that Vivek's vanity could influence the content of his experience. He suggests that it therefore isn't a purely empirical question whether Vivek's vanity can influence his experience - or more generally, whether cognitive penetration can occur.

I agree that question for Psychology presupposes a philosophical thesis about experience, but McDowell and I disagree about what this thesis is. I think the thesis is that there's such a thing the phenomenal character of perceptual experience that can be congruent with what one fears, wants, suspects, or knows. The kind of cognitive penetration I discuss is influence on the contents associated with phenomenal character. Exactly which underlying metaphysical structure experiences have is irrelevant to whether cognitive penetration is possible. What matters is that cognitive states can affect phenomenal character.

On the first position McDowell mentions, experience is exhausted by acquaintance with items in the environment, and bringing them under concepts occurs in response to experience. Contents come into the picture only with the application of concepts. When a face looks approving to Vivek, he entertains the content "the face is approving", but this content is not a content of experience.

As I use the notion of experience, it is individuated by phenomenal character. So if bringing an item under a concept makes a phenomenal difference to perceptual experience, then this is a content of experience in the relevant sense. McDowell says that Brewer's Object View is a version of this analysis. But Brewer allows that bringing a concept to bear on an object of acquaintance can affect the phenomenal character of the perceptual experience. ${ }^{8}$ One might want to reserve "experience" for the acquaintance relation, while allowing that the phenomenal character of perceiving can be affected by applying concepts to things with which one is acquainted. So long as the phenomenal character is part of what it is like to perceive, there is cognitive penetration.

\footnotetext{
${ }^{8}$ Brewer (2011), p. 123 claims that the transition from something "thinly looking F" to "thickly looking F" can be a phenomenological change. Brewer seems to hold that every such transition would be phenomenal change. I would dispute that, as it seems implausible that if I hear a note and move from not knowing which note in the scale it is to knowing that it is A-flat will necessarily make it sound differently in any phenomenal sense. Brewer's own example in which someone learns that a shade of blue is navy blue also strikes me as a poor candidate for a perceptual phenomenal change. Other cases of coming to apply a concept are stronger candidates for introducing phenomenological changes, such as noticing an iguana hidden in a bush (differentiation), or categorizing some of trees in a mixed copse as pine trees, or coming to recognize that a certain sequence moves in a dance is a recurring sequence.
} 
The second analysis McDowell mentions allows that experiences have contents but limits those contents to ones that involve low-level properties, and so would exclude the property of being a face. Here what matters is whether the low-level properties exhaust the phenomenal character of experience. If they do, then Vivek's case can't be a case of cognitive penetration. But cognitive penetration in general isn't limited to effects on highlevel properties such as being a face. Suppose Vivek's vanity influences the exclusively lowlevel contents of his experience to include ones that normally lead us apply the concept "approving face". Then the interface between experience and judgment would be epistemically okay but the experience itself, on my view, would lose epistemic power.

The empirical question of whether there is cognitive penetration is easiest to state in terms of the contents of experience, but does not make any presumptions about the fundamental structure of perceptual experience. What matters is that there are properties presented to the subject that shape the phenomenal character of their perception. Part of the interest of the Factive Explanatory Constraint as I see it is that it seems to stand or fall with cognitively impenetrable acquaintance. ${ }^{9}$ To reject the constraint is to allow that there could be epistemically good cognitive penetration of acquaintance.

McDowell's second point is that we can safely allow that Vivek is rational to endorse his experience, in which faces look approving, Vivek seems (to himself) to be in a position to know that things are as they appear. He isn't in such a position, and that is an epistemic shortcoming of sorts, but not one that redounds poorly on Vivek. Merely seeming to be in such a position doesn't constitute any kind of irrationality. So Vivek can rationally take his experience at face value.

I can agree with all of this up until the last step. Suppose we grant with McDowell that it is rational for Vivek to believe his eyes, because Vivek has grounds for the judgment available to him. His grounds are that he seems to be in position to know that things are as they appear. Here Vivek has a route to the belief that the faces are approving via the higherorder belief about his experience. ${ }^{10}$ He might reason like this:

P1. I'm in a position to know how things are on the basis of my experience.

P2. I have an experience according to which the faces express approval.

P3. If I have an experience according to which the faces express approval when I'm in a position to know how things are on the basis of my experience, then the faces express approval.

Conclusion: The faces express approval.

P1 is false (relative to a context in which Vivek is the speaker), but I'm granting for the sake of argument that Vivek is rational to believe it.

My claim is that Vivek is irrational to believe that the faces approve, on the basis of his experience. His experience does not support his belief. The issue isn't whether Vivek can

\footnotetext{
${ }^{9}$ I discuss the constraint in section 3 of my first-round contribution.

10 Gupta makes a similar point in his first-round contribution, as does Smithies (2018).
} 
end up a rational belief that the faces are approving on some other basis. The issue is whether his experience as of approving faces provides him with reason to think this.

The argument above bypasses this aspect of his experience, if that experience is not meant to be grounds for any of the premises. If Vivek has one set of epistemic resources that both exclude his experience as of approving faces and support his judging that the faces approve, that situation is compatible with having another epistemic resource - his experience as of approving faces - that cannot support this judgment. If he actually forms the judgment, then which status the judgment has depend on which set of resources he uses to arrive at the judgment.

Of course in a normal case, he would presumably simply judge on the basis of his experience, rather than bothering with the higher-order reasoning.

These observations point us to a potential ambiguity in what it is to take an experience at face value. I've been using this notion as if it builds in that one forms the judgment that $p$ on the basis of one's experience that presents one with $\mathrm{p}$, or with an object $\mathrm{o}$ and property $\mathrm{F}$ such that the proposition $\mathrm{p}$ is the proposition that o is $\mathrm{F}$. One could use it more liberally, to mean that one judges that $p$, when one has such an experience, but forms the judgment on some other basis, such as the reasoning higher-order beliefs about the position one is in. Either way, the crucial issue is whether Vivek can form a rational belief by judging that $p$, on the basis of a hijacked experience with content $p$. The argument McDowell sketches does not weaken the pressure to hold that forming a judgment on that basis would be irrational. It simply identifies a different route by which Vivek could arrive at that judgment.

\section{Works cited}

Brewer, B. (2011) Perception and it Objects. Oxford University Press. Jenkin, Z. (ms) Perceptual learning and reasons-responsiveness. Siegel, S. (2017) The Rationality of Perception. Oxford University Press. Smithies, D. (2018) Comment on Siegel. Analytic Philosophy 64. Zeimbekis, J. (2013) “Color and cognitive penetrability” Philosophical Studies 165(1): 16775 . 